University of Louisville

ThinkIR: The University of Louisville's Institutional Repository

Electronic Theses and Dissertations

$5-2011$

\title{
Teenage pharmapocalypse? : an exploratory examination of prescription drug abuse.
}

Lorin Brooke Friley

University of Louisville

Follow this and additional works at: https://ir.library.louisville.edu/etd

\section{Recommended Citation}

Friley, Lorin Brooke, "Teenage pharmapocalypse? : an exploratory examination of prescription drug abuse." (2011). Electronic Theses and Dissertations. Paper 461.

https://doi.org/10.18297/etd/461

This Master's Thesis is brought to you for free and open access by ThinkIR: The University of Louisville's Institutional Repository. It has been accepted for inclusion in Electronic Theses and Dissertations by an authorized administrator of ThinkIR: The University of Louisville's Institutional Repository. This title appears here courtesy of the author, who has retained all other copyrights. For more information, please contact thinkir@louisville.edu. 


\title{
TEENAGE PHARMAPOCALYPSE?: AN EXPLORATORY EXAMINATION OF PRESCRIPTION DRUG ABUSE
}

\author{
By
}

\author{
Lorin Brooke Friley \\ B.A., University of Louisville, 2011 \\ A Thesis \\ Submitted to the Faculty of the \\ Graduate School of the University of Louisville \\ In Partial Fulfillment of the Requirements \\ For the Degree of \\ Master of Arts \\ Department of Communication \\ University of Louisville \\ Louisville, Kentucky
}

May 2011 


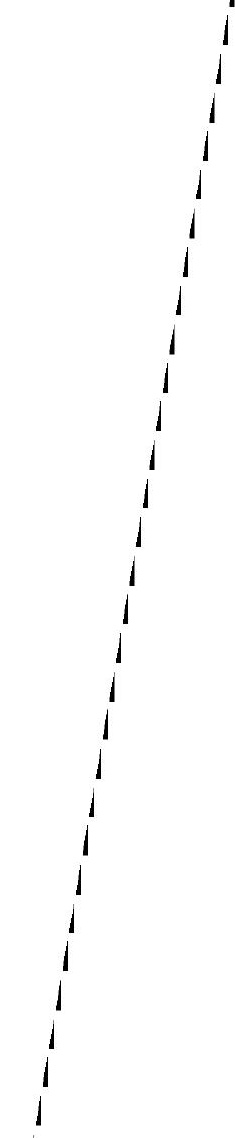


TEENAGE PHARMAPOCALYPSE?: AN EXPLORATORY EXAMINATION OF PRESCRIPTION DRUG ABUSE

By

Lorin Brooke Friley

B.A., University of Louisville, 2011

A Thesis Approved on

April 4, 2011

by the following Thesis Committee:

Kandi L. Walker

Kandi L. Walker, Ph.D.

Lindsay J. Della

Lindsay J. Della, Ph.D.

Elizabeth Grossi

Elizabeth Grossi, Ph.D. 


\section{DEDICATION}

This thesis is dedicated to my late cousin, Derek Walter, who showed us that sometimes goodbye is a second chance. 


\section{ACKNOWLEDGEMENTS}

This thesis would not have been possible without the encouragement and support of many important people. First, I would like to thank my thesis advisor, Dr. Kandi Walker, for being my academic "mother." Dr. Walker has been a constant source of encouragement throughout my graduate program and without her reminders to breathe I may very well have forgotten to do so. Also, this thesis project would not have been successful without her guidance, input, and of course, editing. I would also like to thank the other members of my committee, Dr. Lindsay Della and Dr. Elizabeth Grossi, for their enthusiastic support of my project and for providing me with a wonderful and educational thesis experience. In addition to my committee, I would also like to thank the Department of Communication faculty and staff for their support and interest in my project. I would also like to thank my parents, Dan and Dawn Feltrop, for constantly supporting me in all of my endeavors, for always pushing me to do my very best, and for teaching me to make education a priority. Lastly, I would like to thank my colleagues and friends for their support of my project and for always being willing sounding boards when things got tough. 


\section{ABSTRACT \\ TEENAGE PHARMAPOCALYPSE?: AN EXPLORATORY EXAMINATION OF PRESCRIPTION DRUG ABUSE \\ Lorin Brooke Friley}

April 4, 2011

The purpose of this study was to examine the phenomenon of teenage prescription drug abuse in Jefferson County, Kentucky to gain a better understanding of the environment and characteristics of a teenager who abuses prescription drugs, and to gain insight into this situation through the perspectives of adult professionals who regularly work with teenagers. In-depth interviews were conducted with five professionals, and data analyses were performed to determine recurring themes. There were four primary emergent themes, including: profiling of a teenage prescription drug abuser; factors influencing likelihood of drug abuse; portfolio of mental, emotional, and social issues; and treatment processes. There was general consensus among interviewees that there is no "typical" profile of a teen who abuses prescription drugs. There are many convening factors that contribute to the likelihood a teen will abuse prescription drugs, including peer influence and familial influence. Teens who abuse prescription drugs generally present with a multitude of mental health issues, coping difficulties, and social struggles. If a teen who is abusing prescription drugs receives treatment, there are generally many cycles of unsuccessful treatment programs prior to a success. 


\section{TABLE OF CONTENTS}

PAGE

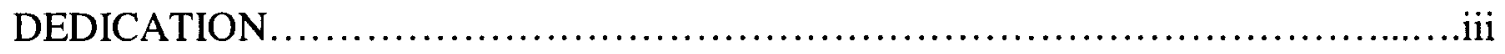

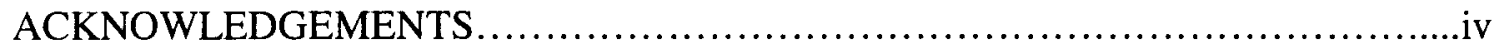

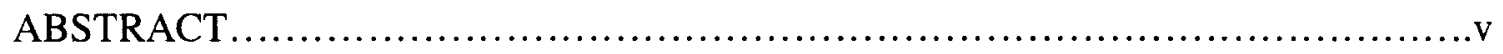

INTRODUCTION/LITERATURE REVIEW.....................................

What is Prescription Drug Abuse? ....................................................................

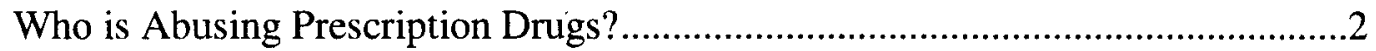

Effects and Consequences of Teenage Prescription Drug Abuse...................4

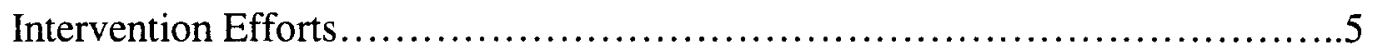

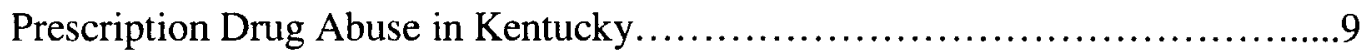

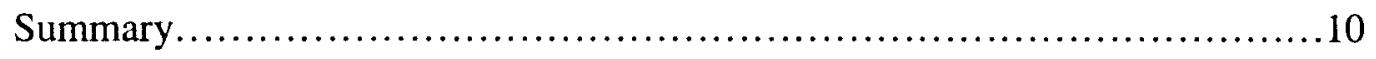

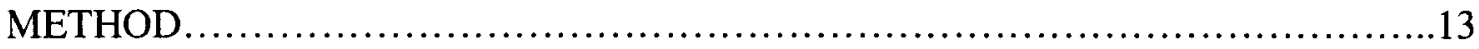

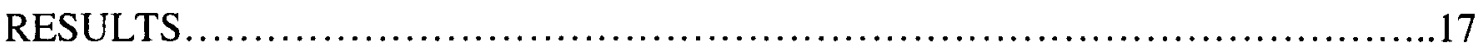

Predictors of a Teenage Prescription Drug Abuser.............................17

Factors Influencing Likelihood of Drug Abuse..............................20

Portfolio of Mental, Emotional, and Social Issues............................23

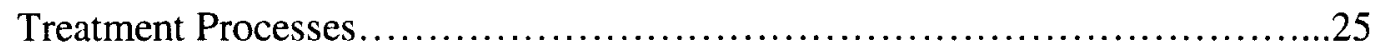

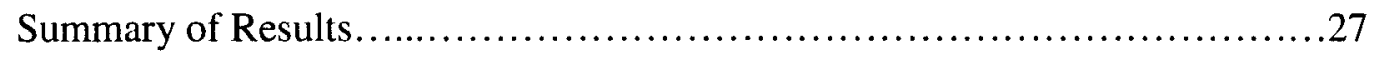

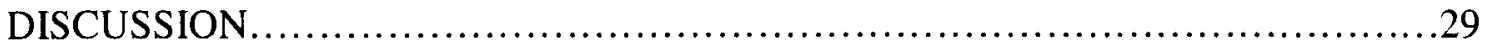

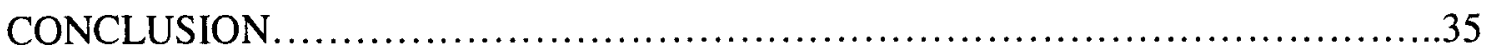




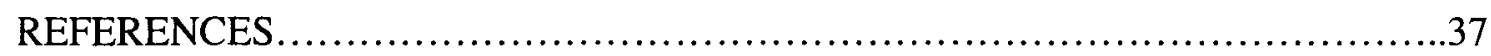

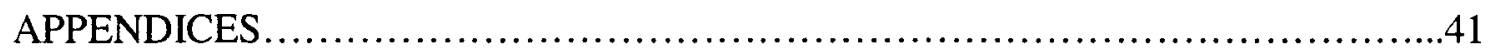

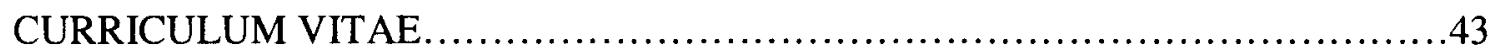




\section{INTRODUCTION/LITERATURE REVIEW}

What is Prescription Drug Abuse?

According to the National Institute on Drug Abuse (NIDA), prescription drug abuse is the act of taking any prescription drug for nonmedical purposes, such as getting high, losing weight, or building muscle (2006, p. 2). Additionally, according to NIDA (2006, p. 2), prescription drug abuse may include the abuse of a variety of drugs including painkillers, anti-anxiety medications, stimulants, and steroids. Research indicates that this phenomenon of prescription drug abuse is an ever-increasing problem in the United States (Arkes \& Iguchi, 2008, p. 1027). Additionally, according to Higgins, Mahoney, \& Ricketts (2009, p. 949), "the nonmedical use of prescription drugs has gained significant attention over the last decade and is increasingly becoming a public health concern." This problem, unfortunately, is affecting not only adults but also teenagers. Moreover, prescription drug abuse is not a new problem for adolescents. In fact, prescription drug abuse among teens has been an evolutionary process that has been developing for more than thirty years.

Evolution of Prescription Drug Abuse. According to the Substance Abuse Mental Health Services Administration (SAMHSA), from the 1980's to 2000, the number of young adults abusing prescription drugs increased from 400,000 to 2 million (2006). This staggering increase is reflected in data collected by both SAMHSA and NIDA over the past nine years. For example, NIDA reported that in 2002, 4.7 million Americans abused prescription drugs for the first time (NIDA, 2010). NIDA (2010) further reported that in 
$2003,4 \%$ of youth ages 12 to 17 reported abuse of prescription drugs in the month prior to data collection. According to SAMHSA (2006), in 2004 approximately 15 million Americans ages 12 years and older abused prescription drugs. Again, according to NIDA, in $2008,2.9 \%$ of youth ages $12-17$ years old abused prescription drugs (NIDA, 2008). It is apparent from this data that teenage prescription drug abuse is an exponential problem, but the magnitude of the problem itself is also revealed in several research studies that directly surveyed adolescents about substance abuse patterns.

Magnitude of the Problem. According to one study, nationally, in 2002, 7.6\% of adolescents ages 12 to 17 years old acknowledged nonmedical use of prescription pain pills (Sung, Richter, Vaughan, Johnson, \& Thom, 2005, p.44). Additionally, Arkes and Iguchi $(2008$, p. 1028) collected data regarding nonmedical use of prescription drugs. They found $10.5 \%$ of $12^{\text {th }}$ graders used Vicodin and $4 \%$ of $12^{\text {th }}$ graders used Ritalin. They also noted that many of the youth surveyed were unaware that Vicodin is a narcotic. Not surprisingly, prescription drug abuse now accounts for about one-third of drug abuse in the U.S. (Katz et al., 2008, p. 588). There are also more first-time drug users abusing prescription drugs than marijuana (Katz et al., 2008, p. 588). While it is clear teenage prescription drug abuse is a problem, it is also important to recognize specifically which adolescents are abusing prescription drugs, how these adolescents are obtaining the drugs, and if possible, why adolescents are abusing prescription drugs. Who is abusing prescription drugs?

Population Description. Many research studies present varied findings indicating what type of adolescents are abusing prescription drugs, one such study found that "females, older adolescents, whites, and individuals from low-income families 
constituted the higher-risk groups for misuse" (Sung et al., 2005, p. 46). It is also indicated in research that adolescents with other underlying issues may be more likely to abuse prescription drugs. Accordingly, Sung et al., found that "the abuse of narcotic pain killers was also associated with delinquent activities, antisocial behavior, and mental health problems (Sung et al., 2005, p. 46)."

Reasons for Prescription Drug Abuse. There are many documented reasons that attempt to explain why adolescents are abusing prescription drugs. The primary reason, according to research, appears to be the availability of the drugs. Commonly, teenagers are obtaining these substances from the medicine cabinets in their own homes, and from friends or family members who have valid prescriptions for these medications (Kentucky Office of Drug Control Policy, 2010). According to NIDA (2006), one in four teens with a valid prescription has been asked by a friend for pills. Concordantly, the availability of prescription drugs has increased due to an increase in the amount of prescriptions being written (NIDA, 2006), and availability has also increased due to the prevalence of online pharmacies that do not require a valid prescription (www.prescription-drug-abuse.org).

There are also several research studies that indicate why teenagers may be abusing prescription drugs versus other types of substances (or in conjunction with other substances). According to NIDA, teenagers may believe prescription drugs are safer to abuse than other drugs because they are prescribed by a doctor and come from a pharmacy (NIDA, 2006). Additionally, if a teenager is already abusing other drugs, he or she may be exhibiting substance abusing behavior that leads to the abuse of prescription drugs (NIDA, 2006). Another such study found that teenagers may be abusing prescription drugs to get high, fit in socially, or assist in academic studies (Arkes \& 
Iguchi, 2008, p. 1028). Regardless of the reasons why teenagers abuse prescription drugs, it is very important to recognize the consequences of prescription drug abuse to teenagers.

\section{Effects and Consequences of Teenage Prescription Drug Abuse}

Physical Effects. The physical consequences of prescription drug abuse are often the most noticeable, damaging, and at times, devastating of all consequences. Of the utmost concern is the fact that using prescription drugs in a manner other than prescribed can result in a fatal overdose (NIDA, 2006). However, there are also symptomatic consequences for surviving drug abusers. According to www.painfullyobvious.com, prescription drug abuse is associated with uncontrollable diarrhea, vomiting, and nausea; body function disruptions (e.g., excessive sweating, urination, or thirst), drowsiness, dizziness, shaking, insomnia, severe and extensive rashes, hospitalization, and death. Also disturbing is the reality that the chemical interference of drugs (e.g., prescription drugs) with the developing adolescent brain can cause stunted development, cognitive disabilities, and irreversible chemical imbalances (Jackson, Usher, \& O'Brien, 2006). Lastly, and most concerning, is the idea that due to a still-developing brain, teenagers are more susceptible to addiction and are more likely to become life-long drug abusers (Jackson, Usher, \& O’Brien, 2006). In addition to physical consequences, teenage prescription drug abuse also comes attached to a plethora of emotional consequences.

Emotional Effects. The website, www.painfullyobvious.com, outlines eight warning signs of prescription drug dependency including: 1. acting especially angry or abusive, or engaging in reckless behavior, 2. getting into significant trouble at school or

getting significantly lower grades, 3. lying or acting secretive or deceptive, 4 . possessing 
unexplained valuables or cash, 5. hanging around a different group of friends, 6 . acting withdrawn, depressed, or apathetic, 7. neglecting appearance or hygiene, and 8 . violating curfews or running away (www.painfullyobvious.com). Finally, there are also social consequences associated with teenage prescription drug abuse.

Social Effects. Although social consequences do not present the imminent danger that overdosing presents, social consequences can have long-term devastating effects on a teen's mental capacity, leading to continued substance abuse problems. According to the Painfully Obvious website, teenagers abusing prescription drugs can be ostracized by their social networks for their using and abusing habits (www.painfullyobvious.com). Despite the obvious possibility that teenage prescription drug abuse may rise to epidemic proportions, and the gravity of the consequences presented to teens who abuse prescription drugs, the occurrence of interventions specifically aimed at teenage prescription drug abuse is relatively low when compared to other drug intervention programs. Additionally, teenage prescription drug abuse is not currently at the forefront of many substance abuse prevention initiatives.

\section{Intervention Efforts}

According to Morris, Cline, Weiler, and Broadway (2006), "despite a recent increase in prescription drug abuse among adolescents and young adults, the problem has received only limited attention from public health policy analysts and prevention specialists (p. 34)." There are some school-based initiatives associated with substance abuse prevention. According to Morris et al., "Given the relative absence of a national prescription drug abuse prevention initiative, school-based educational programs likely constitute the most common mechanism by which young people learn about the potential 
consequences of prescription drug abuse (Morris et al., p. 34)." Although current substance abuse prevention initiatives for teens may not thoroughly address prescription drug abuse, there are a handful of programs currently addressing general teenage substance abuse. Many of these initiatives target parents of adolescents.

Public Health Campaigns Targeting Parents. One of the well-publicized of these initiatives is the Parents: The Anti-Drug campaign (www.theantidrug.com). This program is sponsored by The National Youth Anti-Drug Media Campaign, and is targeted directly at parents of children and teenagers. The Anti-Drug campaign is designed to give parents the resources and information they need to talk with their children accurately and effectively about drug use, and the guideposts needed to identify when their child may be abusing drugs. The campaign offers tips and tools for prevention, as well as tips, tools, and resources for addressing a drug problem. This campaign primarily reaches parents through an extensive website containing informative articles, advice and information from other parents and professionals, and links to resources that parents can get in contact with if they are in need of professional assistance. Parents can also sign up to receive an electronic newsletter containing more drug-related information and parenting tips. The campaign also provides a wealth of downloadable literature to assist parents.

Additionally, NIDA actually has a working program to assist parents with helping prevent their teenage children from abusing substances. This government funded organization exists under the umbrella of the National Institutes of Health (NIH) and publishes and distributes a research-based guide to assist parents in drug abuse prevention. The guide, called the Redbook, explains and promotes research-based drug prevention programs within communities. In addressing parents, the guide recommends 
that parents join with other members of their community to select research-based drug prevention programs for their teenagers. There are also a few initiatives that target teenagers to prevent substance abuse.

Public Health Campaigns Targeting Teenagers. The most well-publicized of these campaigns is Above the Influence (www.abovetheinfluence.com). This program was recently redesigned in June 2010 to "catch up" with teen trends and present a fresh message to an overburdened teenage audience. This program is part of the National Youth Anti-Drug Media Campaign, a larger program sponsored by the Office of National Drug Control Policy (a government-based agency). The campaign aims to use messages collected from teens, for teens to help them identify peer influences and determine how to make good decisions for themselves while experiencing these influences.

The campaign employs television and print advertisements, and runs an extensive website. The website provides information about all types of drugs, including alcohol, and addresses other peer pressures (such as sex) and mental health conditions (including depression). The campaign generally comes across as targeting younger teenagers, and some sections of the site provide information about drug myths, which clearly targets a more naïve audience. The site also provides several interactive activities for teens to learn actual biological and chemical components of drug use. This campaign began a focus on prescription drug abuse in 2008, and boasts a successful return on investment.

According to the campaign website, awareness of teen prescription drug abuse increased $116 \%$ following the launch of related advertisements. The campaign conducts evaluations via exploratory research, qualitative analysis (what the site terms as focus groups), quantitative analysis (what the site terms as copy testing), tracking studies, and 
national surveys such as the National Survey on Drug Use and Health

(www.abovetheinfluence.com).

There is also the Check Yourself campaign. This campaign is supported by the Partnership for a Drug-Free America, which is a private and non-profit organization that addresses drug use issues with children, teens, adults, parents, families, and other groups. The Partnership is a nationally recognized program that essentially connects with all types of people and groups about all types of drug issues. The Check Yourself campaign is targeted toward older teenagers who may be looking for more in-depth information about substance abuse or have difficult and specific questions about drugs that other resources cannot address.

This campaign relies primarily on its website to disseminate messages, and presents a variety of unique interactive opportunities for teens to express their own ideas about drug use. This program encourages teens to think about how they would handle situations where they are confronted with a choice about drug use, and also encourages them to share their thoughts on this decision-making process with other teens on the site. It also includes testimonials from real teens who have used drugs in the past. The Partnership uses a scientific advisory board to conduct quantitative research providing results about the current drug usage trends, and also consults with actual parents of teenagers to determine what current trends are developing among the actual teen population (http://checkyourself.com).

Public Health Campaigns Targeting Prescription Drugs. As previously mentioned, there is one campaign that specifically addresses teenage prescription drug abuse, the "Painfully Obvious" web-based campaign. This website is targeted toward 
both teenagers and parents. The home page is primarily a starting point for teenagers to learn about prescription drugs, familiarize themselves with the names of commonly abused drugs, understand the definition of prescription drug abuse, and learn about some consequences of the abuse. The majority of the website is devoted to parents and includes a number of free resources such as pamphlets and questionnaires, as well as many guides designed to assist parents when talking with their children about prescription drug abuse. The website also includes several tip sheets for parents to assist them in identifying prescription drug abuse with their own children, and lists several outside resources where parents and teenagers can find other information or professional assistance with a prescription drug abuse problem. Although teenage prescription drug abuse is clearly a national problem in the United States, this issue is of particular concern to the state of Kentucky.

Prescription Drug Abuse in Kentucky

Nature of the Problem. Prescription drug abuse in Kentucky has actually surpassed the use of crystal meth, the former drug of choice for many Kentuckians (aside from marijuana). In the year 2006-2007, 8.3\% of Kentucky children ages 12-17 years old abused prescription drugs (Kentucky Office of Drug Control Policy, 2007). Teenage prescription drug abuse in Kentucky has been increasing rapidly over time, and minimal research has been conducted to understand this phenomenon (Carlson, Stinger, Stevens, \& Sterk, 2009, p. 59).

Prescription Drug Monitoring Programs. Kentucky became the first state, in 2002, to implement an electronic prescription drug monitoring system, eKasper, to track the prescribing and distribution of controlled substances (Crosse, 2004, p. 3). This 
monitoring system has helped Kentucky reduce the diversion of prescription drugs by decreasing the investigation time of prescription drug cases, creating a deterrent for doctor shopping, reducing legal costs associated with prescription drug cases, and increasing the number of arrests and prosecutions of prescription drug-related offenders (Crosse, 2004, p. 3).

\section{Summary}

Research, as noted by Arkes \& Iguchi (2008, p. 1027) clearly indicates that prescription drug abuse in the United States is an increasing problem. Moreover, as demonstrated by SAMHSA and NIDA, prescription drug abuse among adolescents has been on the rise for an extended period of time. Disturbingly, statistics indicate that prescription drug abuse may be outpacing other popular forms of substance abuse among adolescents (namely, marijuana). The majority of research studies examining teenage prescription drug abuse indicate a wide variety of physical, mental, social, and emotional characteristics among this population (Sung et. al, 2006; Arkes \& Iguchi, 2008; NIDA, 2006). Most studies also indicate a wide variety of physical, mental, emotional, and social consequences that are associated with adolescent prescription drug abuse (NIDA, 2006; Jackson, Usher, \& O'Brien, 2006; www.painfullyobvious.com).

Unfortunately, as noted by Morris, Cline, Weiler, \& Broadway (2006, p. 34), little research has been conducted to thoroughly examine this phenomenon in terms of possible intervention efforts. Adding to the problem, the majority of current public health campaigns addressing teenage substance abuse do not specifically address prescription drugs. Following national trends, teenage prescription drug abuse is on the rise in Kentucky (KODCP, 2007). Accordingly, although the research mentioned indicates that 
prescription drug abuse is a problem in Kentucky, particularly among adolescents, researchers have not delved deeply into the phenomenon of teenage prescription drug abuse in Kentucky, namely, Jefferson County, in order to examine precisely what occurs in the world of teens who abuse prescription drugs. Higgins, Mahoney, \& Ricketts (2009, p. 950) support this idea in their findings which indicate, "Some research has been focused on the perceptions of occurrence of the nonmedical use of prescription drugs, but less research has been focused on the reasons why this behavior occurs."

Therefore, this study seeks to examine teenage prescription drug abuse from the perspectives of adult professionals who regularly work with teens, with the purpose of creating a clearer picture of teenage prescription drug abuse in Jefferson County through the use of in-depth interviews. The researcher interviewed several key informants based on a model presented by Leukefeld, Walker, Havens, Leedham, \& Tolbert (2007), to gain insider perspectives on teenage prescription drug abuse. The researcher chose the key informants for the interviews based on the parameters for selection presented by Cicero et. al, (2007) which indicate that key informants should be "well-recognized experts in the field (in this case teenage prescription drug abuse)," and "are in a position to evaluate, treat, or otherwise know about new and emerging drug problems in their areas (p. 162)."

The researcher examined this phenomenon by asking questions regarding the interviewees' thoughts and perceptions of teenage prescription drug abuse in general, reasons why adolescents may be abusing prescription drugs, what the general life environment may be like of a teen who abuses prescription drugs, and what some consequences of prescription drug abuse may be for adolescents. Thus, the following four research questions may be posed: 
RQ1: How do adult professionals perceive teenage prescription drug abuse?

RQ2: What are some reasons adult professionals believe teens are abusing prescription drugs?

RQ3: How do adult professionals describe the social, physical, and emotional lives of a teen who abuses prescription drugs?

RQ4: What do adult professionals believe are the consequences to a teen who abuses prescription drugs? 


\section{METHOD}

\section{Introduction}

This phenomenological study was intended to explore the issues of teenage prescription drug abuse in Jefferson County (Louisville), KY. In order to evaluate the research questions posed within this study, the researcher conducted a qualitative study comprised of a series of in-depth interviews and performed subsequent thematic analysis to draw recurring themes from the data. This section of the research report will outline the study sample selection process, data collection process, and data analysis process. Study Sample

Recruitment. First, the researcher obtained approval for this study from the Institutional Review Board. The researcher then obtained contact information for potential participants from departmental advisors who were familiar with the study. Potential participants were contacted by phone with the opportunity to participate in the study. No incentives were offered to participants.

Selection of Participants. Sampling for this study was purposive and convenient. Based on the concept of key informant interviews, the potential participants who were contacted were asked to take part in an interview if they are an adult professional in Jefferson County whose employment requires regular contact with teenagers. If the contact indicated willingness to volunteer for the study, an interview time was setup for the researcher to meet at the interviewee's place of employment (or another convenient location). 
Description of Sample. The sample of participants for this study included 5 total adults, 3 males and 2 females. All interviewees were employed full-time (40+ hours per week) and held some type of university degree. Interviewees regularly work with teenagers in the capacity of legal work, rehabilitation services, substance abuse counseling services, and addiction counseling services.

Data Collection. Informed consent was obtained from each participant prior to the interview. Interviewees were read an interview script in order to clarify the purpose of the study and what exactly was required of each participant. This script was modeled after the key informant study conducted by Carroll, Craypo, Harper, \& Samuels (2000). All of the interviews occurred in the interviewee's place of employment $(n=5)$ and lasted 40 minutes to 77 minutes ( $M=48.3$ minutes). Interview times did not include explanation and signing of the consent form or study description. Interviewees were informed of audio recording procedures and given the opportunity to ask questions about the study.

Interview Procedures. Interviews for this study were semi-structured and openended. The interviews were conducted in-person and audio recorded on a digital recorder. The semi-structured, open-ended interview guide was designed to provide a framework of data in which the researcher could work, but also allowed the participants to respond to the questions in various ways as the researcher developed probing questions based on participant responses.

Instrumentation. The interview guide consists of eight primary questions that encouraged the interviewees to explain their thoughts and perspectives on teenage prescription drug abuse, and also to describe how they view the social, physical, and emotional components of a teenaged prescription drug abuser's life. The interview guide 
also asks participants to discuss the consequences to teens who abuse prescription drugs. The interview guide was created based on a model from the key informant study conducted by Carroll, Craypo, Harper, \& Samuels (2000). The questions in the interview guide were arranged topically, so as to begin with an opportunity for the interviewee to openly express his or her thoughts about teenage prescription drug abuse in general; then moving on to discuss the social, physical, and emotional components; followed by consequences to a drug-abusing teen; and finally concluding with an open-ended opportunity for the interviewee to include any information that was not discussed previously within the interview.

The interview guides contains the following questions: (a)"What do I need to know about teenage prescription drug abuse?”, (b)“How do you think teenage prescription drug abuse differs from other types of teenage drug abuse?", (c)“What are your thoughts on teenage prescription drug abuse?", (d)“What are some of the biggest problems you see with teenage prescription drug abuse?", (e)“Why do you think teenagers abuse prescription drugs?”, (f)“Describe what you would consider a "typical” teenage prescription drug abuser to be like.", (g)"What do you think the social environment is like for a teenager who is abusing prescription drugs?", (h)"What do you think the physical environment is like for a teenager who is abusing prescription drugs?", (i)"What do you think the emotional life is like of a teenager who is abusing prescription drugs?”, (j)“What do you think the actual consequences are to a teenager when he or she is abusing prescription drugs?”, (k)"What do you think teenagers perceive the consequences to be?", and (1)"Is there anything else about teenage prescription drug abuse that I need to know and did not already ask about?" 
Data Analysis. Five interviews were conducted, which included one 40-77 minute interview per participant $(M=48.3)$. The interviews were transcribed as Microsoft Word documents, and included a total of four hours of audio recordings and 72 typed pages of transcripts. After the interviews were transcribed, the data were imported electronically into QDA Miner, a qualitative data analysis program. The data were analyzed in multiple phases using thematic analysis techniques. Initially, the data were coded for preliminary themes by examining the transcripts for recurring ideas throughout the interviews and marking significant keywords associated with recurring ideas. This preliminary coding set of keywords was then organized into categories that best described the recurring themes. These categories were then reduced into larger "umbrella" categories that best represented the data. The categories were evaluated to ensure that each category appropriately described the accompanying data and was inclusive of the various themes. Once it was determined that the categories were exhaustive, there were enough identifiable themes to begin addressing the proposed research questions. 


\section{RESULTS}

From these in-depth interviews, four overarching themes emerged: profiling of a teenage prescription drug abuser; factors influencing likelihood of drug abuse; portfolio

of mental, emotional, and social issues; and treatment processes. The following sections will examine these four themes and include direct statements from the interviewees as concrete support of the themes.

Predictors of a Teenage Prescription Drug Abuser

The first theme discussed was Profiling of a Teenage Prescription Drug Abuser. This theme emerged when participants were asked to provide a general summary of their thoughts and perceptions of teenage prescription drug abuse, and also as participants were asked to describe a "typical" teenage prescription drug abuser. The general consensus that surfaced is that when attempting to "profile" a "typical" teenage prescription drug abuser, it is nearly impossible to do so. Each adult interviewee indicated that there are no general parameters surrounding teenagers who abuse prescription drugs that would allow an adult to visually "pick out" a teenager who is abusing prescription drugs from a random group of teenagers. There are no demographic indicators (race, ethnicity, socioeconomic status, geographic location), no real physical indicators (sex, progression of physical development), and often no specific behavioral indicators (depressed versus not depressed, physically aggressive versus passive) prior to abuse. 
When asked to describe a typical teenager who abuses prescription drugs, one interviewee responded, "No, I can't answer that question because you see it in all walks of life, across socioeconomic lines; it's not dictated by anything other than the individual. All walks of life, like snowflakes." Additionally, when prompted by the suggestion that many stereotypes exist as far as the background of teens who abuse prescription drugs, the interviewee stated:

I'm assuming the stereotype is you're talking about upper middle class people who for whatever reason the public feels take prescription drugs. Well, everyone takes prescription drugs. The poorest of the poor, the richest of the rich. That completely defeats the stereotypes because just as everyone across socioeconomic lines takes prescribed drugs, so too do they abuse them. So too do juveniles within each social strata abuse those drugs. So I think that it's an artificial and baseless stereotype.

The same interviewee also expressed this thought:

There are preconceived notions that the only kids who have issues or have problems which manifest themselves in delinquent behavior are those who don't have two parents in the home and are socioeconomically disadvantaged. That is not the case. They come in every conceivable classification or environment that you can conceive. It isn't the reality of the situation that external factors dictate how an individual juvenile reacts. It's back to the individual, him or herself. Now am I telling you that those external factors absolutely play no role on the individual? I'm not telling you that. What I'm telling you is that you cannot look 
at the external factors as have any sort of predictive success saying that a person is going to end up abusing substances. That's just not the reality of the situation. In fact, the only trend interviewees could identify as an outward indication of teenage prescription drug abuse was that there are few limitations as to which teens will and will not abuse prescription drugs. In other words, prescription drug abuse is not a discriminatory problem. This is not to say, however, that interviewees did not provide several types of commonalities when describing teenage prescription drug abusers, which will be mentioned in other themes, but commonalities generally did not enter the interviewees' descriptions until discussing teens who had already begun abusing prescription drugs.

In regard to predictive evidence, one interviewee did identify some basic indicators that can signal a problem, "Unfortunately, one of the leading predictors is just grade point average, so if they have a D or below then it's a very nice predictor of criminal activity, criminal activity is a nice predictor of substance abuse and vice versa. And you have poverty level of course. What's interesting, in one of the bigger surveysstudies-I'm sorry, is that grade point average, or D average in the school was a much stronger predictor than poverty level or income."

When discussing the problem of teenage prescription drug abuse in general, the interviewees did agree that prescription drug abuse is very spontaneous and opportunistic for teens, and often occurs when a teen is under the influence of other substances (alcohol and marijuana). Thus, it can be said that a teen that is presented with many opportunities to obtain a prescription drug may be more likely to abuse these substances. One interviewee explained this scenario well, he stated: 
There seems to be a period of habit forming when, you know, of course just like adult behavior, after the habit is formed they're going to seek it [the substance] more actively, consciously, think about it. There are fewer habits, you know, with judging by the frequency of use and numbers of use, there's less habit with the pill use and the kids on pills, it is almost all impulsive behavior. So, it's kind of erroneous to say peer pressure, it's almost like, peer opportunity. And if you're at a party and someone has them [pills] and they are already drinking or high, and someone you know says 'hey I've got these Xanax, you want to try it?' You know, and that, 'sure!' And that's, that's what a lot of the kids report. So 'I don't seek it, but when it's there sometimes I take it, I usually have to be high to take it.' I get that report a lot.

Therefore, as explained by the interviewee, pinpointing a teen who will abuse prescription drugs essentially comes down to "Who has the opportunity?" There are virtually no demographic indicators, and the profiles of teens who do abuse prescription drugs are as varied as, according to the previously cited interviewee, snowflakes.

\section{Factors Influencing Likelihood of Drug Abuse}

The second theme that emerged from the data was Factors Influencing Likelihood of Drug Abuse. This theme began to emerge as participants were asked why they believe teens abuse prescription drugs, and also as participants were asked to describe the physical, social, and emotional environments of teens who are abusing prescription drugs. The interviewees generally agreed that there are two specific avenues of influence that may encourage teens to abuse prescription drugs. These avenues are peer influence and familial influence. 
Peer influence, according to the interviewees, did not fit the stereotypical mold of "peer pressure," but rather, peer influence was described by the interviewees as social circles where prescription drugs are openly passed around and shared between friends, with use being completely at the discretion of the individual teen, but acceptance of the use being universal. That is to say, peers are not necessarily pushing their friends to engage in prescription drug abuse, but are openly accepting, at times encouraging, and sometimes enabling friends to abuse prescription drugs. As one interviewee stated, "Sure, I like the word acceptance, you know. If you, there's two, two factors involved, you got your peers, opportunity, but then the kids seeking acceptance, so there's, if , if you want to talk about it as pressure, there's two pressures but it's equal, you know, own, your own pressure, then someone else's."

The interviewees' personal definitions of peer pressure and peer influence should be noted. It appeared from the interviews that each of the interviewees maintains a fairly outdated definition of peer pressure, that is, the stereotypical idea that peer pressure exists in the form of one exceptionally troubled teenager moving from peer group to peer group and forcing other teenagers to engage in risky behavior such as substance abuse. Peer influence, as described by the interviewees, exists in the form of highly tolerant and accepting peers who may or may not engage in risky behavior, but do not shun individual teens who choose to experiment or engage in risky behavior, and may actually encourage those teens to do so. Interestingly, the interviewees' definitions of peer influence is similar to the modern working definition of peer pressure, which has eliminated the idea of one peer who pressures, but accepts the idea of many peers who do not necessarily pressure but accept and encourage risky behavior. 
Some of the interviewees referred to peer circles, where groups of friends openly pass around whatever pills they are able to obtain to anyone who wants them, in a friendly pill-trading ring. One interviewee mentioned, "What is more common though, is, I think, is part of gang affiliated behavior. I don't mean, I don't mean gangs, I mean gang age, in your teenage years, looking for acceptance, looking for power, control, them to have pills and show them around and try to appear like something they're not, a drug dealer or something else."

In addition to peer influence, the interviewees also discussed familial influence. The interesting thing about familial influence, as several of the interviewees explained, is that it comes in two forms- hereditary and generational. According to the interviewees, substance dependency and predisposition to addiction are inherited mental disorders. Therefore, if a teen has parents or other family members who abuse substances or suffer from addiction issues, it is highly likely that teen will also suffer from one or both problems at some point in his or her life. Substance abuse is also generational in the sense that it can certainly be a learned behavior. That is, if a teen has parents or family members who abuse substances, particularly prescription drugs, it is highly likely he or she will end up abusing the same substances in the same manner because he or she has been conditioned to accept, understand, and follow those behaviors. It is a case of the ultimate "monkey see, monkey do."

One interviewee described this concept anecdotally:

If I have a kid charged with possession of a controlled substance, and this is not the first possession of a controlled substance charge that that particular kid has had, it's obvious that there's a substance abuse issue. If I somewhere down the 
road find out that that kid's parent, mother, father, what have you, or caregiver even, him or herself has a substance abuse issue, my general reaction to that is that makes sense. Because I think in a lot of cases particularly with regard to the topic at hand, we mimic what we observe. I think that's human nature, again anecdotally. Certainly, and I believe that there is some level of scientific evidence to support this, that it [substance abuse] is genetic on some level. Predispositions to substance abuse, so certainly if a blood relative has that issue, I'm not surprised when the juvenile in front of me has the same issue [substance abuse]. Or that same issue [as the family member]. So in that regard I guess there's a bit of a predictive criterion to judge things on.

It is clear, based on the information provided by this interviewee, that it is difficult to separate what behaviors a teen learns from his or her family, and what behaviors a teen is unfortunately predisposed to or susceptible to because of his or her family history. Portfolio of Mental, Social, and Emotional Issues

Portfolio of Mental, Social, and Emotional Issues was the third theme that emerged from the data. This theme generally began to emerge as participants were asked to describe the physical, social, and emotional environments of the teens. One of the interviewees in particular discussed what he called the "portfolio" of issues a teenager has when he or she abuses prescription drugs. This interviewee explained that this portfolio is generally revealed during the treatment process for a teen who is already abusing prescription drugs. The portfolio he references is essentially a long list in a teen's medical chart of mental health conditions, emotional abuse, physical abuse, sexual abuse, violent or criminal behavior, and so on. 
This interviewee explained:

Well, most of them [teenage substance abusers] have trauma history. Now the populace in general of co-occurring youth, $60-80 \%$ of the panel we surveyed, has a trauma history. With the pill use kids it's a little higher. What you can expect with kids with abuse or trauma history is 5 or more problems [diagnoses], on the average. Or 5 or more symptoms of diagnoses, I guess is the way to put it. So if you looked at their [medical] chart, you know, they have what looks like a shotgun approach to a diagnosis. There's tons of, you know, diagnosable problems. That tends to be your, the ones [teens] that are generalized being marijuana users, will start having more complicated histories.

It is essentially a "chicken or the egg" phenomenon when a teen becomes a prescription drug abuser. That is to say, did the teen begin abusing prescription drugs and then engage in criminal behavior and develop mental health issues? Or did the teen already struggle with mental health issues or a history of abuse, and end up abusing prescription drugs as a coping mechanism?

Another interviewee stated, "Most of the kids that we see in juvenile court have a host of issues. And many times that would include substance abuse and substance abuse of prescription drugs. Again, we live in a pill world. You can't turn the TV on without seeing a commercial for this, that, or the other. And because that is the case in this society in which we live that gives access to a cacophony of substance abuse or controlled substance options for juveniles."

He also said: 
I think that a kid who's abusing anything but with regard to prescription drugs, is a kid that needs to be examined further to determine whether he or she might have a problem down the road that this is just the beginning stages of what may later become a much bigger problem. And that bigger problem not only manifests itself in abusing other substances but also everything that comes with that abuse. Theft, in order to fund the habit, for want of a better term. Behavior while under the influence of that substance. So it, I believe, is an opportunity to prevent a whole host of problems down the road with regard to abuse of other drugs and the behaviors that spring from that.

The former interviewee explains the significance of this problem in his discussion of treatment processes also, as this portfolio of issues makes treating adolescent substance abuse particularly difficult and also increases the likelihood of recurring abuse cycles, or relapses.

\section{Treatment Processes}

The fourth theme that emerged from the data was Treatment Processes. This theme most often presented when participants were asked to discuss the actual and perceived consequences to teens who abuse prescription drugs. This theme also emerged when participants were asked to discuss what they believe is the biggest problem associated with teenage prescription drug abuse. The interviewees agreed that treatment processes for teens who abuse prescription drugs are complicated for several reasons.

The first reason is primarily the fact that teens who abuse substances are more likely to suffer from long-term addiction issues because of the early onset of substance abuse. It is well-known, and the interviewees confirmed this fact, that the earlier a person 
begins to abuse substances, the more likely it is he or she will suffer from addiction issue for many years, if not his or her entire life. According to one interviewee:

If you use substances before the age of 15 then you'll likely have a 27 year career of use unless you get to treatment within the first year or so, then you shorten that career to 9 years. Within that 9 year success bubble, so you know it's a $300 \%$ gain [shortening from 27 years to 9 years], you know that's still 9 years. The average treatment episode will occur 3 or 4 times, 3.5 times, 3 or 4 times in that 9 years. Relapse is the norm, which means, repeat, repeat, repeat. I looked at our kids here last year from June to July. It was over 400 kids, the average number of treatment layers [cycles] just in Seven Counties Services was 5.8. You know, so, so recurring treatment is the theme. These kids struggle everywhere. And including treatment, ambivalence is the definition for their age. Turns out, they'll reoccur in their problem for awhile, so [the first treatment is] definitely not the end and within the treatment episodes you're talking about different levels of care that they'll go up and down the ladder. Yeah so I'd say that's [treatment] not the end but it does get finer tuned, how about that? So several [criminal] charges are also the norm too though. So repetition of treatment but also repetition of getting caught. So for the first few times, you know, we'll see a kid, we'll have nice 6 month treatment episode with them, they'll do better, either drop off the face of the earth or we graduate them. We'll see them again but it'll be under the same conditions for the next round. They'll get caught doing something else stupid but for the third or fourth time we see them it doesn't tend to be, it tends to be a little bit more self initiation, the parents calls or they call. They're trying to prevent 
their incarceration or legal trouble. So the carrot and stick is the juvenile court system and the treatment provider working together.

Another reason treatment is often unsuccessful is that it can be very difficult for teens to be placed into the treatment programs they need, because parental involvement and the structure of the legal system often prevent teens from being required to receive treatment. When treatment is not required, parents and teens may not agree to treatment programs. One interviewee describes this process, "So that's the other factor of the pill use that bothers me, is that when we do need extensive intervention service, such as send them over to the hospital, get them basically detoxed, and medically monitored while they do so, then make some decisions about the ongoing treatment, that usually is a hassle because it's so infrequent and you know the, pretty much, child care is setup to be least restrictive first."

Another interviewee expressed similar sentiments, "We find that many of the kids who are involved with the department of juvenile justice have substance abuse issues including abuse of prescription drugs. The probation officer would certainly put, certainly should put in place treatment options for that juvenile and hopefully again address what it is and in this case we're talking substance abuse that's leading to the delinquent behavior."

Therefore, it can be very difficult for a substance abuse or addiction counselor or a legal professional to do his or her job of getting a teenager who is abusing substances into the treatment program he or she needs because both parents and the legal system as a whole are constantly interfering with the process of getting teenagers into treatment. Summary of Results 
It is very difficult to accurately describe a teen who is abusing prescription drugs, or to predict which teens will end up abusing prescription drugs. Based on the interviews conducted, it is obvious that the issue of teenage prescription drug abuse does not discriminate among who it affects. Any teenagers at any time could become involved with this problem. However, there are some factors that indicate the likelihood of abusing prescription drugs may be higher for some teens. Those factors generally stem from the teen's peer circles of influence and from the family history and environment of the teen. If a teenager comes from a family with a history of substance abuse or dependency, or any history of addictive behavior, it is likely that teen will struggle with one or more of the same issues, which could include the abuse of prescription drugs.

There are also many co-occurring factors that may exist in a teenager's life that may contribute to or be attributed to prescription drug abuse. Those factors include mental, social, and emotional issues such as abuse, depression, or social anxiety. Lastly, if a teenager does become involved in prescription drug abuse, it can be very difficult for that teen to receive the treatment he or she needs. Due to parental involvement (and reticence to admit their child into a treatment program), the structure of the legal system, and the covertness of prescription drug abuse, many teens pass through several unsuccessful cycles of treatment that may never end in complete recovery. 


\section{DISCUSSION}

Although drug abuse, specifically prescription drug abuse, has a clear definition, there are very few clear cut facts available when discussing teenage prescription drug abuse. Among the few clear cut facts that do exist are the statistics indicating teenage prescription drug abuse is on the rise, the fact that teens are very susceptible to prescription drug abuse due to influence and easy access, and the indications that teenagers are abusing prescription drugs for a wide variety of reasons. The results of this study indicate that there is no specific profile of a teen who abuses prescription drugs, there are many factors which may influence a teen's likelihood to abuse prescription drugs, there are generally a portfolio of factors influencing a teen to abuse prescription drugs, and teens who do abuse prescription drugs may not receive the treatment they need and it may not be effective.

As reflected in the study, when looking at teenage prescription drug abuse, it is difficult to pinpoint one specific type of teen or one specific cause that indicates teenage prescription drug abuse. These findings correlate with the research projects about prescription drug abuse that present a widely varied description of the teenage populations who are abusing prescription drugs. The interviewees indicated that there is no specific profile of a teen who abuses prescription drugs, making teenage prescription drug abuse a largely individual and specific phenomenon.

It is interesting, based on the data collected in the interviews, to note that although each interviewee indicated that he or she was unable to specifically describe a teenage 
prescription drug abuser, he or she was often able to pinpoint several characteristics of a teen who is likely to end up abusing prescription drugs. Therefore, it can be asserted that while there are no demographic indicators, or profiling characteristics, of a teen who is a prescription drug abuser, there are certain indicators the interviewees have noted as commonalities among teens who abuse prescription drugs (such as poor academic performance, mental health issues, violent or criminal behavior).

There are certain co-occurring factors that are generally present in teens who are abusing prescription drugs. As discussed with the "portfolio" of issues, these factors often include mental health issues, such as depression or bipolar disorder. There are also histories of emotional issues often stemming from physical or verbal abuse during childhood. Additionally, there may be social issues such as difficulties in school, difficulties making friends, and lack of social abilities. The interviewees discuss a "portfolio" of issues that are attached to many teens who are abusing prescription drugs. This response is a direct reflection of research by Sung et al. (2005), who found that abuse of pain pills was tied to these types of factors.

Teenagers who abuse prescription drugs may be influenced by peers, family members, or both. As indicated by several studies including those studies conducted by NIDA and KODCP, teenagers often obtain prescription drugs from family members (whether being given the drugs or stealing them) and peers (through pill passing from peer to peer). The interviewees also supported this data, discussing the peer circles to which teens belong where pills are widely accepted, shared, and traded. Additionally, all of the interviewees agreed that the majority of teens who abuse prescription drugs obtain them from family members, whether by raiding the medicine cabinet or by receiving 
them from family members who also abuse substances. Interviewees indicated that a family history of prescription drug abuse strongly contributes to the potential that a teen will abuse prescription drugs.

It is also important to consider the source of these influences on teens from a theoretical standpoint. It is understood that both peers and family influence teens in regard to abusing prescription drugs, but it is not clear from the interviews precisely where the family influence originates. The generational influence discussed by the interviewees may originate as either a behavior of imitation (simply teens emulating the behavior of their family members), or as an actual learned behavior (teens following the same pattern as family members because the behavior is demonstrated, learned, and accepted by the teens as a purposeful habit).

Unfortunately, despite the prevalence and obvious risks associated with prescription drug abuse, many teens who are abusing these substances do not receive effective treatment. The interviewees in this study discuss the series of treatment cycles many teens go through on their journey to recovery. Sadly, as the interviewees point out, most teens who receive treatment for substance abuse do not recover after the first treatment program, and probably not after many subsequent treatment programs. This recurrence can result in many serious, long-term problems, as research indicates that teens who begin abusing substances at a very early age will likely enter several cycles of recovery and relapse, and may never fully recover from using. Jackson, Usher, and O'Brien (2006) mention this risk in their research, as they state that early drug abuse is more detrimental to the brain than late-onset drug abuse. 
The results of this study present several indications of areas where further research about teenage prescription drug abuse is needed. As the interviewees pointed out, there are no solid indicators to use in identifying a teen that is abusing or is likely to abuse prescription drugs. Further examination of similarities among teenagers who abuse prescription drugs may reveal patterns that exist but simply have not yet been uncovered. This type of research would be best pursued by interviewing teenagers themselves. While adult professionals have very valid opinions regarding teenage prescription drug abuse, in order to fully examine the phenomenon teenagers themselves must be involved in the research process.

Additionally, further research should be conducted to examine what causes exist for substance abuse within families and peer circle. While peer circles are composed of teenagers, and many causes of substance abuse will be similar among those teens, there may be specific factors that cause these peer circles of substance abusers to form. This phenomenon should also be examined at the level of the teenagers themselves, and would be best pursued by examining these peer circles. This research could set a precedent for intervention efforts within the social arenas of teenagers (school, community organizations). Within families there are undoubtedly many factors that contribute to both hereditary and generational substance abuse. Future research should examine family groups to evaluate patterns that may exist among families with substance abuse issues. Determining these patterns may provide an opportunity for early intervention efforts to prevent teens within families from falling into the same patterns.

Looking at the co-occurring factors that precede or indicate teenage prescription drug abuse, it is clear that a great deal of research must be conducted to separate each 
factor from the other and to evaluate how each factor individually convenes with teenage prescription drug abuse. By separating these factors, researchers may be able to evaluate what specific "red flags" exist in a teenager's life that may be the impetus for substance abuse. In understanding these "red flags" researchers may also be able to make recommendations for intervention efforts that address individual causal factors. Therefore future research should focus on one causal factor at a time to evaluate each thoroughly.

Lastly, it is clear that treatment efforts for teenagers who abuse prescription drugs are not producing the most desirable results. Future research should examine both the parameters which dictate how a teenager enters a treatment program, and also the parameters of prescription drug specific treatment programs. In doing so, several things may be revealed, including: factors contributing to failed treatment programs, areas of treatment programs where improvements can be made to improve treatment success, factors that prevent a teenager from receiving the treatment he or she needs, and possible recommendations for adjustments to the parameters dictating how a teenager comes to enter a treatment program (particularly recommendations for increasing the likelihood that a teen will receive treatment).

There are a few limitations to this research study. First, the participant sample in the study is very homogenous. For future studies, sampling could be more diverse in order to represent a broader range of professional opinions and experiences. Changing the sample population would provide richer data and more substantive conclusions. Also, the participant sample could be larger in future studies so as to provide more data reliability and more thorough data saturation. 
Second, the interviewees are all employees within Jefferson County, Kentucky and discussed experiences with teenagers in the same location. The geographic scope of the study could be expanded in future research to include other, similar areas, or simply to include a larger radius for sampling. This change will not only serve to increase the amount of data, but also to allow for comparisons based on geographic location in order to assess geographic influence on teenage prescription drug abuse (which may have an effect on teenage prescription drug abuse in a larger area, whereas interviewees indicated no effect from geographic location within Jefferson County).

Additionally, the coding and thematic analysis for this study was performed by only one researcher. In the interest of intercoder reliability, this study would benefit from being analyzed and coded for thematic analysis by another researcher to ensure reliability as well as evaluate other coding and theme possibilities. This would also present the possibility for new perspectives in data analysis, as well as help to confirm the meaning of the original analyses.

Finally, diverse methodology would also improve this study. By employing other data collecting and data analysis techniques, the results of the study could be greatly enlarged and enhanced. It would be effective to not only expand the sampling methods and geographic scope of the study, but also to include a quantitative component with a survey questionnaire. Including a quantitative component in the research would provide for a mixed methods approach to analysis, which would allow for triangulation of the data. 


\section{CONCLUSION}

In conclusion, this study brings to light many pieces of information associated with teenage prescription drug abuse. It was found that there are several common themes currently being entertained by adult professionals in regard to their perceptions of teenage prescription drug abuse. This research indicates that adult professionals agreed there is no "typical" teenage prescription drug abuser, and that teenage prescription drug abuse is a highly individualized phenomenon requiring highly individualized attention and treatment.

This study also found that adult professionals recognize several factors influencing the likelihood that a teen will abuse prescription drugs, the primary two factors being peer influence and familial influence. The interviewees agreed that substance abuse issues are often facilitated by peers and are both hereditary and generational within families. Additionally, the interviewees indicated that aside from peer influence and familial influence, there are several co-occurring factors (a portfolio) that precede or determine teenage substance abuse. Those co-occurring factors are generally mental health issues, emotional issues, and/or social issues. Most teens who are abusing prescription drugs present with several of these co-occurring factors at any given time.

Finally, teens who abuse prescription drugs are not receiving effective treatment as often as needed. The interviewees indicated that it is difficult for a teen to be admitted into a treatment program due to parental involvement and the structure of the legal system. Also, when a teen is finally admitted into a treatment program, he or she often 
suffers several cycles of relapse and recovery before a final recovery can ever be achieved. Further research should be conducted to determine commonalities among teenage prescription drug abusers in order for researchers to begin identifying "red flag" indicators that precede the onset of prescription drug abuse.

Research should also be conducted to examine contributing factors and influencing factors to teenage prescription drug abuse, that is to say, the factors that are causing teens to abuse prescription drugs as well as the factors that make it likely a teen will abuse prescription drugs. Finally, further research should be conducted to evaluate where treatment programs are failing, in order to determine what improvements must be made to current programs to increase the rate of success. All of these suggestions for future research present opportunities for researchers to make recommendations for better addressing teenage prescription drug abuse, an escalating problem in the state of Kentucky, as well as the United States. 


\section{REFERENCES}

About Check Yourself.com. (2011). Retrieved from

http://checkyourself.com/About.aspx.

About this site. (2011). Retrieved from http://www.abovetheinfluence.com/about.aspx.

About us. (2011). Retrieve from http://www.theantidrug.com/about.asp.

About us. (2011). Retrieved from http://www.drugfree.org/about.

About. (2011). Retrieved from http://www.painfullyobvious.com.

Arkes, J. \& Iguchi, M. Y. (2008). How predictors of prescription drug abuse vary by age. Journal of Drug Issues, 38(4), 1027-1044.

Carlson, R. G., Singer, M., Stephens, R. C., \& Sterk, C. E. (2009). Reflections on 40 years of ethnographic drug abuse research: Implications for the future. Journal of Drug Issues, 39(4), 57-70.

Carroll, A, Craypo, L., Harper, M. H., \& Samuels, S. E. (2000). Key informant interviews and an environmental scan for the California Bone Health Campaign for lowincome Latino mothers. A report to California Project LEAN of the California Department of Health Services and the Public Health Institute.

Cicero, T. J., Dart, R. C., Inciardi, J. A., Woody, G. E., Schnoll, S., \& Munoz, A. (2007). The development of a comprehensive risk-management program for prescription opioid analgesics: Researched abuse, diversion, and addiction-related surveillance (RADARS). Pain Medicine, 8(2), 157-170. 
Commonwealth of Kentucky, Office of Drug Control Policy. (2011). ODCP Media

Center. Retrieved from http://odcp.ky.gov/news/.

Crosse, M. (2004). State monitoring programs may help to reduce illegal diversion. Testimony before the Subcommittee on Health, Committee on Energy and Commerce, House of Representatives.

Higgins, G. E., Mahoney, M., \& Ricketts, M. L. (2009). Nonsocial reinforcement of the nonmedical use of prescription drugs: A partial test of social learning and selfcontrol theories. Journal of Drug Issues, 38(4), 949-964.

Jackson, D., Usher, K., \& O’Brien, L. (2006). Fractured families: Parental perspectives of the effects of adolescent drug abuse on family life. Contemporary Nurse, 23(2), 321-330.

Katz, N., Houle, B., Fernandez, K. C., Kreiner, P., Thomas, C. P., Kim, M.,...Brushwood, D. (2008). Update of prescription monitoring in clinical practice: A survey study of prescription monitoring program administrators. Pain Medicine, 9(5), 587-594.

Leukefeld, C., Walker, R., Havens, J., Leedham, C. A., \& Tolbert, V. (2007). What does the community say: Key informant perceptions of rural prescription drug abuse. Journal of Drug Issues, 37(3). 503-524.

Morris, M. C., Cline, Welch R. J., Weiler, R. M., \& Broadway, S. C. (2006).

PRESCRIPTION DRUG ABUSE INFORMATION IN D.A.R.E. J. Drug Education, 36(1), 33-45.

National Institute on Drug Abuse (NIDA) (2010, September 13). Research Report SeriesPrescription Drugs: Abuse and Addiction, trends in prescription drug abuse. 
Retrieved from

http://www.nida.nih.gov/researchreports/prescription/prescription5.html.

Office of National Drug Control Policy (ONDCP) (2010, September 13). Prescription drug abuse prevention. Retrieved from

http://www.whitehousedrugpolicy.gov/drugfact/prescr-drg-abuse.html

Prescription Drug Abuse (2009). Prescription drug abuse and addiction. Retrieved

September 13, 2010, from http://www.prescription-drug-abuse.org/

Substance Abuse and Mental Health Services Administration (SAMHSA) (2009). Results from the 2008 national survey on drug use and health: National findings (Office of Applied Studies, NSDUH Series H-36, HHS Publication No. SMA 09-4434). Rockville, MD.

Sung, H., Richter, L., Vaughan, R., Johnson, P. B., \& Thom, B. (2005). Nonmedical use of prescription opioids among teenagers in the United States: Trends and correlates. Journal of Adolescent Health, 37, 44-51.

Teen Drug Abuse (2005). Teenage prescription drug abuse. Retrieved September 13, 2010, from: http://www.teendrugabuse.us/prescription_drug_abuse.html.

U. S. Department of Health and Human Services, Substance Abuse and Mental Health Services Administration, Office of Applied Studies. (2008). State estimates of substance use from the 2007-2008 National Survey on Drug Use and Health. Retrieved from http://www.oas.samhsa.gov/2k8state/stateTabs.htm.

U.S. Department of Health and Human Services, National Institutes of Health (NIH) (2006). Prescription drugs: Their use and abuse. Scholastic and the National 
Institute on Drug Abuse (NIDA). Retrieved from

http://www.scholastic.com/headsup.

U.S. Department of Justice, National Drug Intelligence Center (NDIC) (2009). National drug threat assessment: Controlled prescription drugs. Retrieved from http://www.usdoj.gov/ndic. 


\section{APPENDICES}

\section{INTERVIEW SCRIPT}

I am interviewing you because I am interested in finding out more about the problem of prescription drug abuse among teenagers ages 13-17. Currently, very little is known about the behaviors, choices, and actions in which teenagers engage in conjunction with prescription drug abuse. I have chosen you as an interviewee because you work in a capacity where you regularly deal with situations that may pertain to this problem. I want to find out more about the environments and characteristics of these teenagers who abuse prescription drugs, and hope you can provide some valuable insights into the world of teenage prescription drug abuse.

\section{CONDENSED INTERVIEW QUESTIONS}

1. What do I need to know about teenage prescription drug abuse?

How do you think teenage prescription drug abuse differs from other types of teenage drug abuse?

2. What are your thoughts on teenage prescription drug abuse?

What are some of the biggest problems you see with teenage prescription drug abuse?

3. Why do you think teenagers abuse prescription drugs?

Describe what you would consider a "typical" teenage prescription drug abuser to be like.

4. What do you think the social environment is like for a teenager who is abusing prescription drugs? 
5. What do you think the physical environment is like for a teenager who is abusing prescription drugs?

6. What do you think the emotional life is like of a teenager who is abusing prescription drugs?

7. What do you think the actual consequences are to a teenager when he or she is abusing prescription drugs?

What do you think teenagers perceive the consequences to be?

8. Is there anything else about teenage prescription drug abuse that I need to know and did not already ask about? 


\section{CURRICULUM VITAE}

LORIN BROOKE FRILEY

Address: 1242 Cherokee Rd., Apt. 7

Louisville, KY 40204

Phone: 502-851-6250

E-mail: 1bfril01@louisville.edu

\section{RESEARCH INTERESTS}

'Health Communication

-Interpersonal Communication

\section{EDUCATION}

M.A. University of Louisville; Louisville, $\mathrm{KY}$

Projected May 2011 3.97 GPA

-Thesis: An Exploratory Examination of Teenage Prescription Drug Abuse -Advisors: Drs. Kandi Walker and Lindsay Della

B.A.

University of Louisville; Louisville, KY

May 2009

3.11 GPA

Professional Certification, Public Relations Practitioner

2008

December

Russell High School Graduate with Honors

May 2004

\section{PROFESSIONAL EXPERIENCE}

University of Louisville

Louisville, KY

Graduate Teaching Assistant

August 2010-Present

-Independently teaching two sections of Introduction to Public Speaking with total enrollment of 24 students per course; using a combination of textbook and course pack instructional materials to equip students with basic public speaking skills and tools for college success; engaging students in the classroom through various teaching methods including lecture, group activities, individual exercises, one on one instruction, and electronic supplementary instruction.

- Designing and executing a traditional college introductory course by creating a course syllabus and schedule; creating group and individual activities to evaluate student progress, including: written assignments, in-class activities, quizzes, and speeches; 
implementing course policies to ensure student success; using university systems to maintain student grades, attendance, and coursework records.

-In conjunction to teaching, currently enrolled in extensive instructor training programs at the University of Louisville, including a Part-Time Faculty Learning Institute designed to facilitate instructor education and success by covering topics including: developing a teaching persona, employing creative lecture strategies, encouraging students to engage in continuous learning, designing team projects to enhance student learning, using technology to enhance teaching, and developing a teaching philosophy.

University of Louisville

Louisville, KY

Graduate Research Assistant

August 2009-August 2010

- Assisted two professors with tasks related to ongoing research projects, including data collection; data analysis and organization; editing of written research materials; grant proposal submission processes; and research study design.

- Completed independent research exploring topics of self-interest under the supervision of Ph.D. professors; applied research skills learned in graduate courses to construct research projects contributing to thesis preparation; and implemented research best practices in the fields of communication and social science research.

-Developed basic skills associated with teaching at the university level, including grading and grade management, student-professor communication tactics, methods for evaluating students' retention of course material; and maintaining a working balance of teaching and research.

Incredible Dave's, LLC.

Louisville, KY

Party and Event Manager

July 2008-June 2009

-Directed, scheduled, and coached a staff of 17-20 high school students and college freshmen to host children's birthday parties and corporate events.

-Fulfilled several specialized tasks outside of regular management including: designing a structured training program for new party department hires; constructing a systematic approach to data management including profits, guest volume, and growth or decline of parties and revenue; and restructuring the party department to function more efficiently as a whole through effective use of human capital.

-Managed the implementation of parties and events by ensuring employee compliance; utilize effective customer service skills to identify, understand, and defuse guest complaints.

Tumbleweed Southwest Grill

Louisville, KY 
Training Coordinator and Bartender

December 2006-July 2008

-Coordinated new hire process including: conducting orientations; scheduling, preparing, and teaching training classes; coaching a group of 4 trainers to ensure consistency and accuracy among training department.

- Responsibilities included maintaining a cash drawer, demonstrating excellent customer service skills and guest relations, maintaining bar inventory and stock through prepping for day to day operations.

Churchill Downs, Inc

Louisville, KY

Communications Intern

August 2006-December 2006

- Arranged and managed several company events including: quarterly results announcement breakfast, fundraising auction for Disabled Jockeys Fund, chili cookoff.

-Composed and submitted daily press releases to local media, compiled and distributed a weekly newsletter to company departments.

University of Louisville

Louisville, KY

Resident Assistant, Student Orientation Staff

December 2005-December 2006

\section{COURSES TAUGHT}

\section{University of Louisville, 2010-2011}

COMM 111-26: Introduction to Public Speaking, Fall 2010, enrollment 24 students COMM 111-29: Introduction to Public Speaking, Fall 2010, enrollment 24 students COMM 111-23: Introduction to Public Speaking, Spring 2011, enrollment 24 students COMM 111-26: Introduction to Public Speaking, Spring 2011, enrollment 24 students

\section{RESEARCH EXPERIENCE}

Smoking Meta-Analysis Research Team

University of Louisville, 2010-present, supervised by Drs. Kandi Walker and Joy Hart -A meta-analysis of smoking definitions examining research articles published from 2005-2010.

\section{Later Life Research Team}

University of Louisville, 2009-present, supervised by Drs. Kandi Walker and Joy Hart -A qualitative study examining later life men and interpersonal relationship dynamics established via "breakfast clubs."

"Popularity and Facebook"

University of Louisville, 2009-2010, supervised by Dr. Michael Cunningham 
-An experimental study manipulating Facebook profiles to determine correlations between variables such as physical attractiveness, popularity, etc.

Coping with grief through Facebook

University of Louisville, 2009-2010, supervised by Dr. Michael Cunningham

- Varied study including qualitative analysis of Facebook content and quantitative tracking of Facebook usage pertaining to grief, death of Facebook members, and memorializing the deceased.

Data Entry and Analysis-Various Consulting Projects

University of Louisville, 2009-2010, supervised by Dr. Michael Cunningham

-Data collection via surveys, data analysis using Microsoft Excel and PASW Statistics 18.

\section{PRESENTATIONS}

-Magnuson, J. \& Friley, L. B. (2010, August). Something About Coffee and Camaraderie. Presented at the Kentucky State Communication Conference, Prestonsburg, KY.

\section{SERVICE TO THE UNIVERSITY}

-Graduate Student Council Representative

-Graduate Student Council Research Symposium Committee Member

\section{SERVICE TO THE PROFESSION}

-International Association of Business Communicators Student Member

-Kentucky Communication Association Student Member

\section{SERVICE TO THE COMMUNITY}

-Girls On The Run Louisville Volunteer- Public Relations Committee

'Louisville Women's Rugby Club Volunteer- Social Events Coordinator/Public Relations Coordinator/Fundraising Coordinator and Team Member

\section{HONORS AND AWARDS}

-University of Louisville School of Interdisciplinary and Graduate Studies Scholarship Recipient

-Lambda Pi Eta Communication Honors Fraternity

-Who's Who Among American College Students

Golden Key International Honour Society

\section{REFERENCES}

Dr. Kandi L. Walker

Associate Professor

Director of Undergraduate Studies

University of Louisville

Department of Communication

(502) 852-8174

Kandi.walker@louisville.edu 
Dr. Jennifer L. Gregg

Associate Professor

Director of Graduate Studies

University of Louisville

Department of Communication

(502) 852-8177

Jennifer.gregg@louisville.edu

Dr. Lindsay Della

Assistant Professor

University of Louisville

Department of Communication

(502) 852-6976

Ljdell01@louisville.edu

Dr. Al Futrell

Associate Professor

University of Louisville

Department of Communication (502) 852-6976

al@louisville.edu 